\title{
癩に於けら肺臟變化に關する臨床的 並に實驗的研究
}

\section{其 5 「マウス」, 白鼠及家鵎を以てせる實驗}

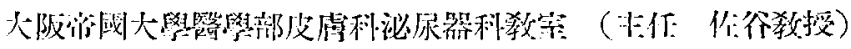
监笨光哭郎

第 1 章 緒

$\overrightarrow{\overline{\bar{F}}}$

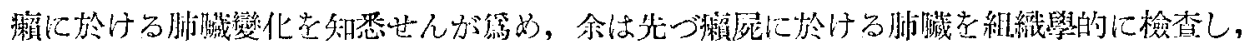

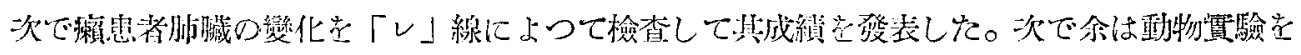

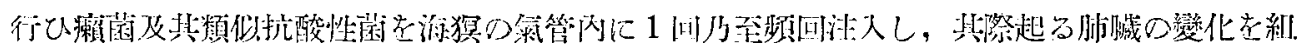

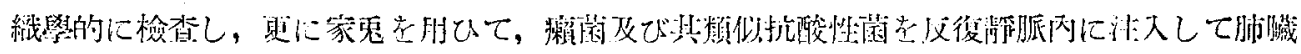

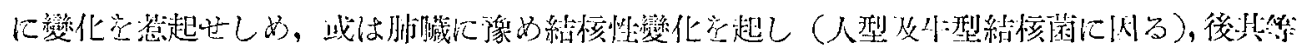

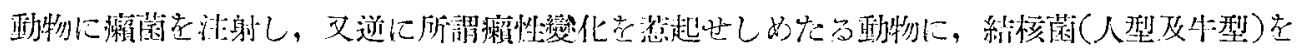

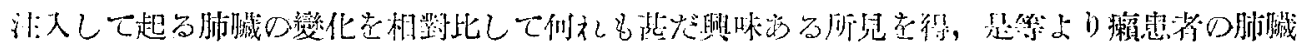

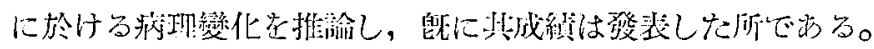

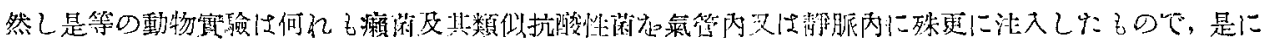

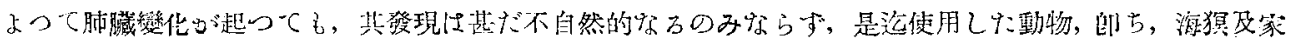

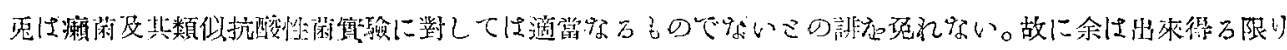

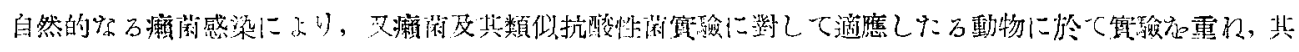

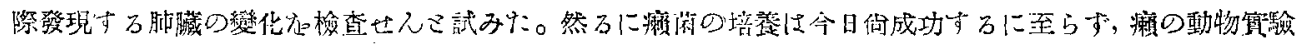

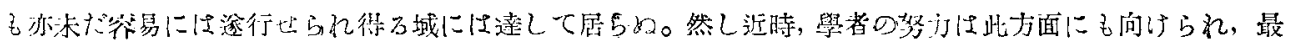

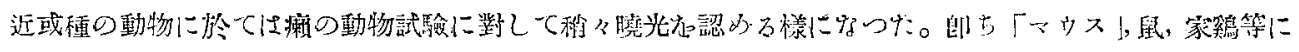

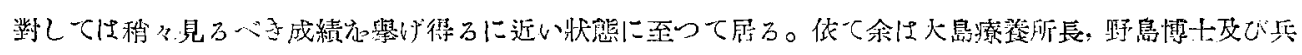

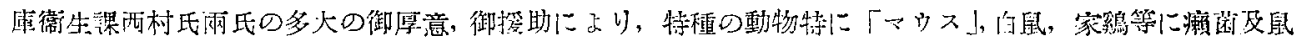

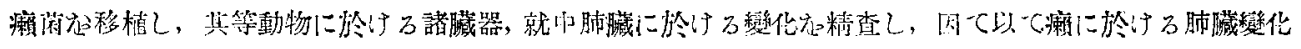

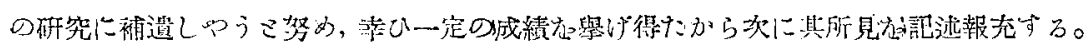

\section{第 2 章＼cjkstart實驗方法及實驗成績}

\section{第 1 節「マウス」を以てせる宽驗}

\section{1）實驗方法}

(19) 


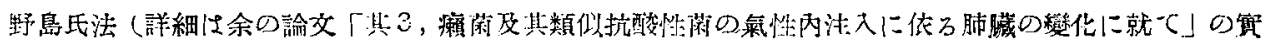

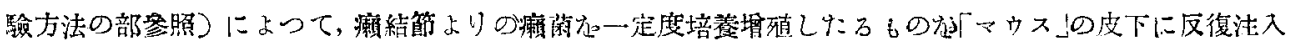

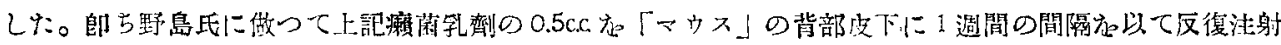

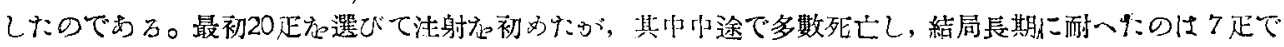

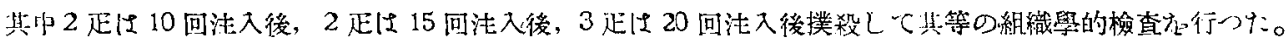

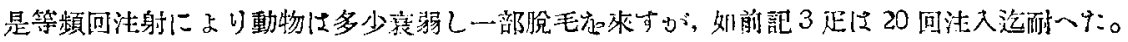

\section{2）實 驗 成 績}

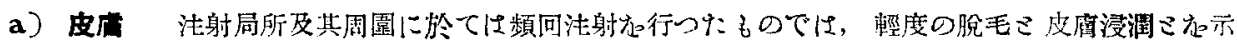

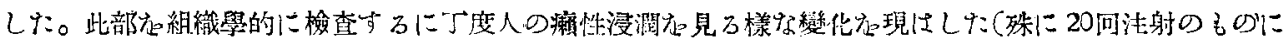

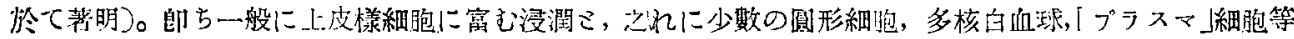

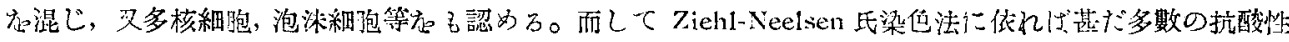

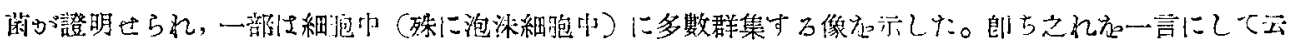

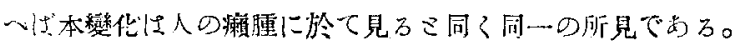

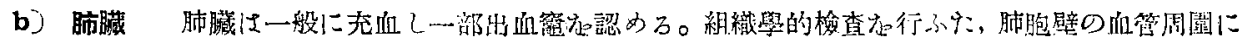

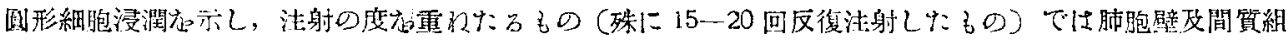

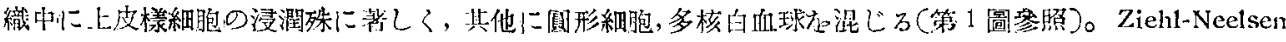

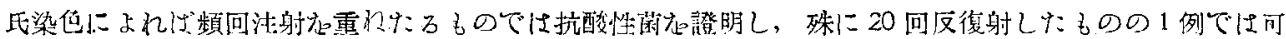

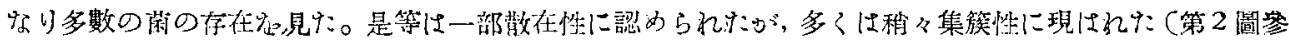
照。

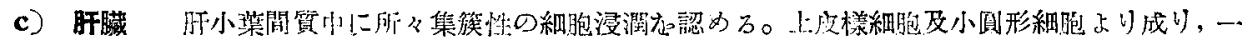

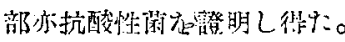

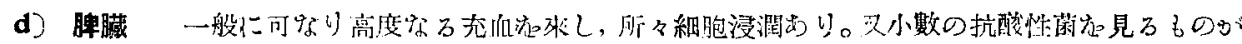
b)

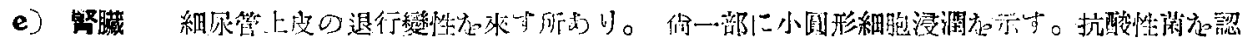
め初加\%。

\section{第 2 節白鼠を以てせる賽融}

\section{1）實驗方 法}

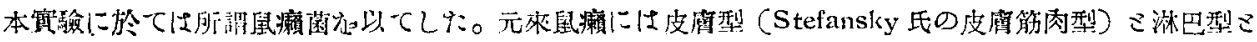

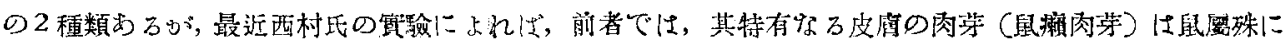

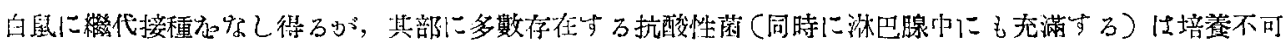

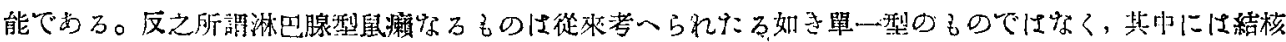

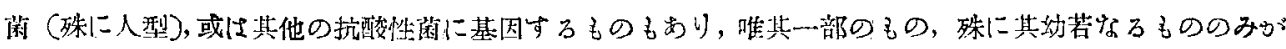

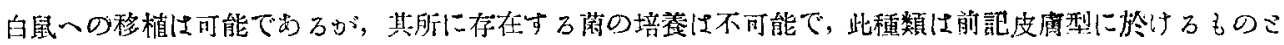




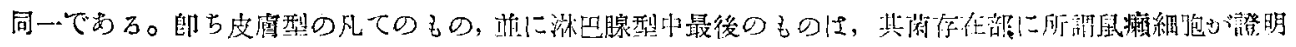

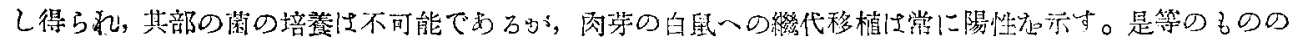

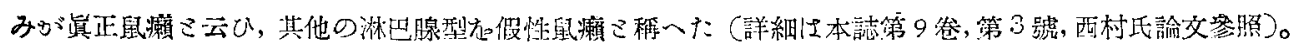

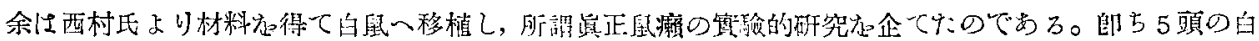

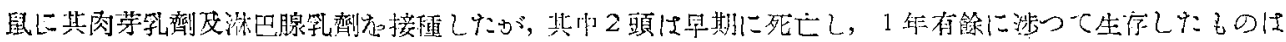

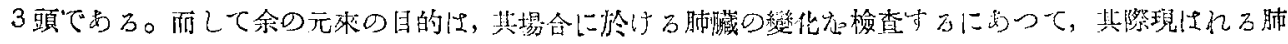

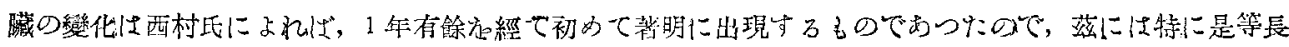
期間生存動物に就ての所見虑詳述寸る。

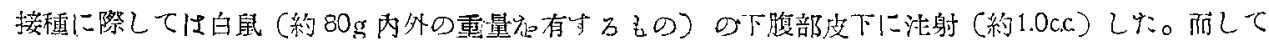

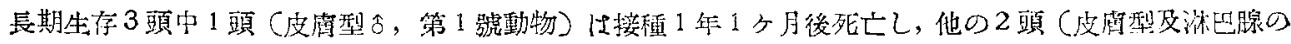

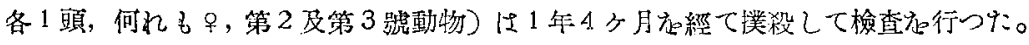

\section{2）貫 驗 成 樍}

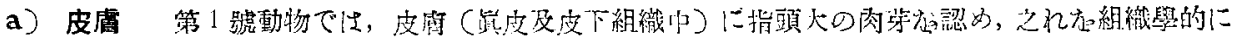

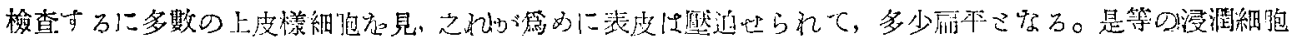

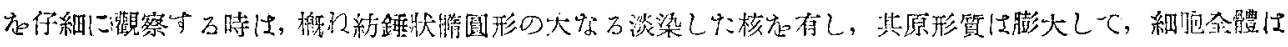
可尔り大子

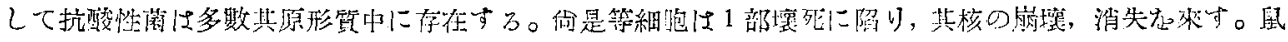

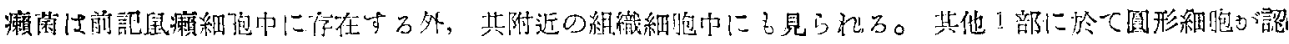

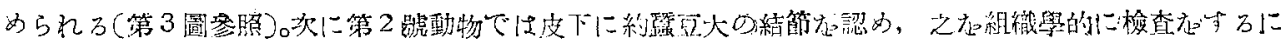

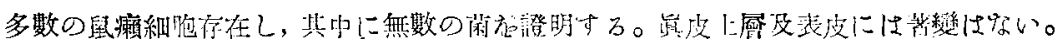

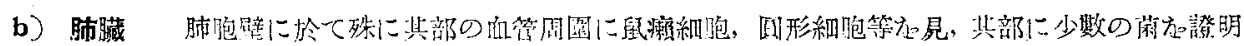

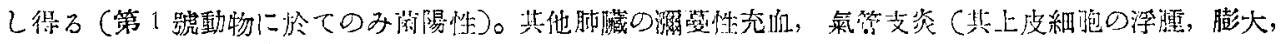

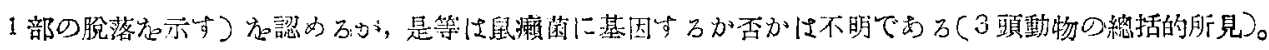

(第4 圖參照)。

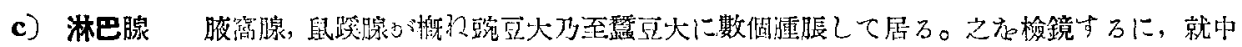

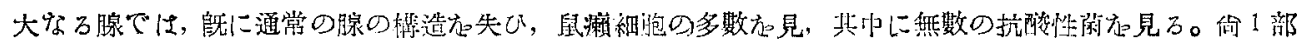
鼠㿎細胞は腺周園の結縍織中にる見られる。

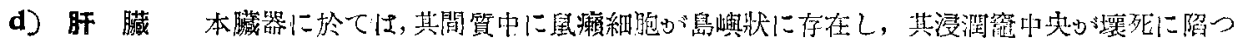

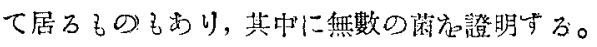

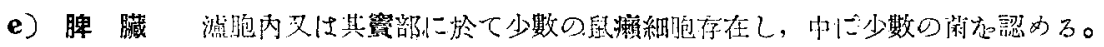

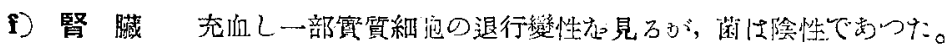

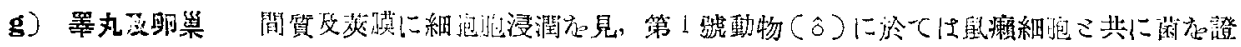
明し得け。 


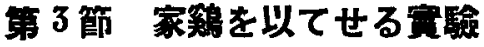

\section{1) 雷 驗 方 法}

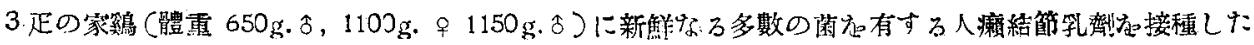

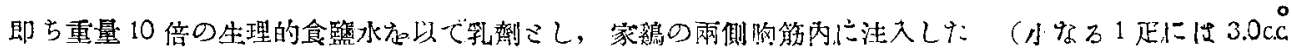

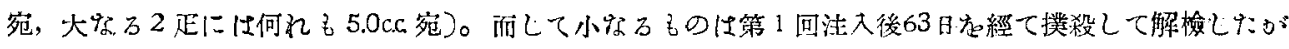

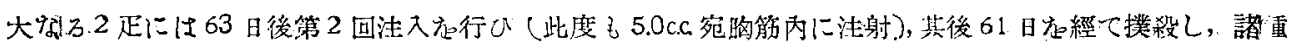

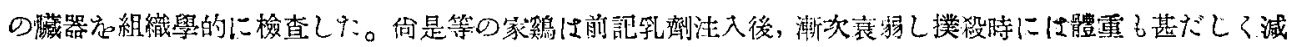
少した（夫ヶ $420 \mathrm{~g}, 650 \mathrm{~g}$. 疝 $870 \mathrm{~g}$. 去示す)。

\section{2）貫 驗 成 績}

3 正に於ける所見は略々同一であるから是等方總括して記还する。

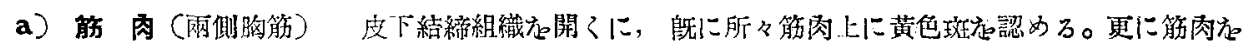

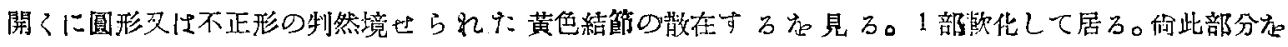

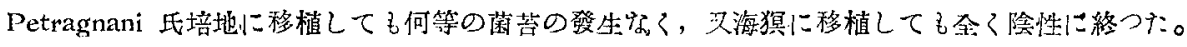

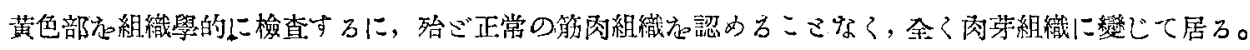
即方多數の上皮樣細胞, 少數の淋巴球より字り, 又「プラスマ」細胞, 多核白血球方混じ, 中に甚ボ多數

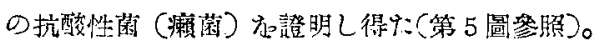

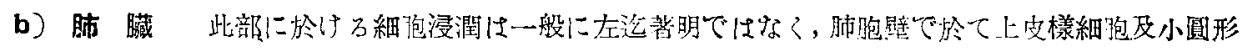

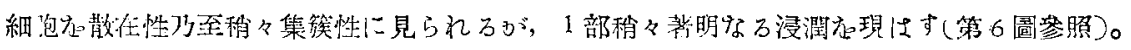

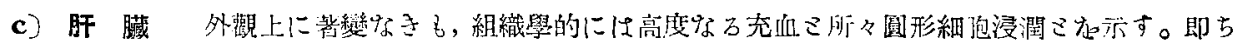

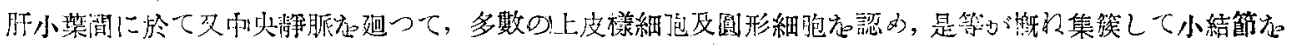
形成主る。何所々に抗酸性足見乃。

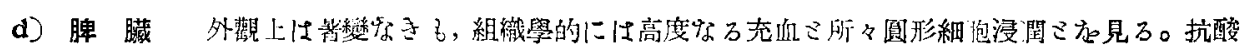
性蒴は證明し得独かつた。

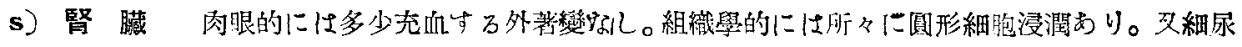

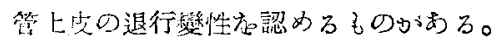

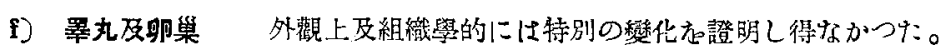

\section{第3章總括及考按}

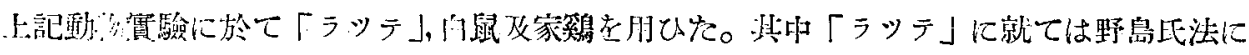

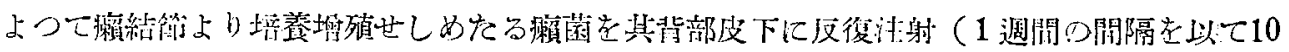

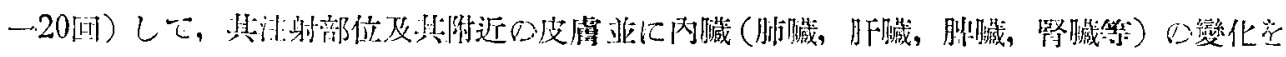

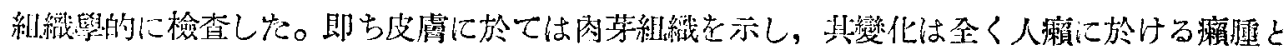




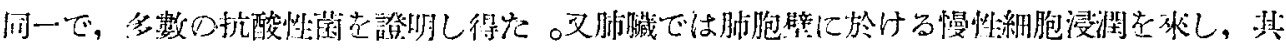

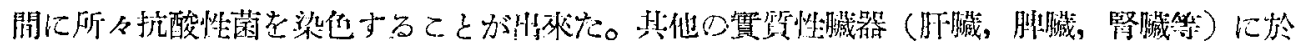

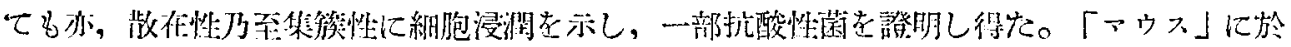

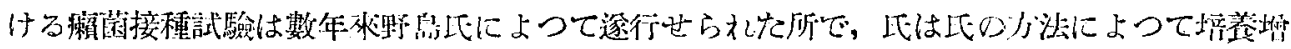

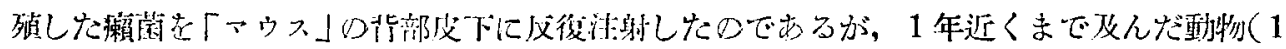

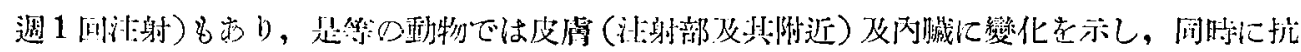

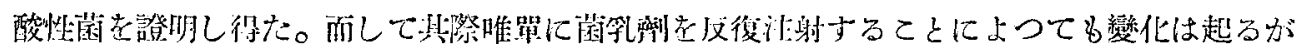

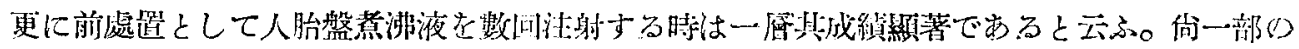

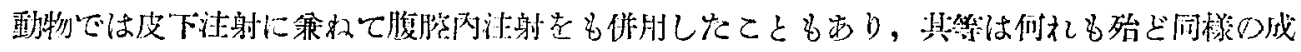

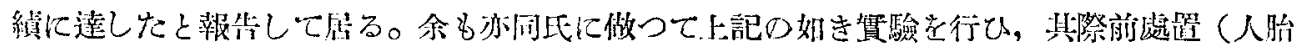

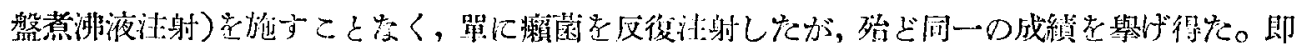

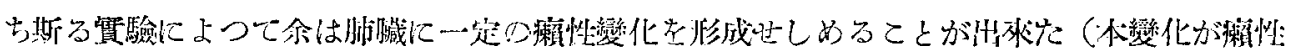

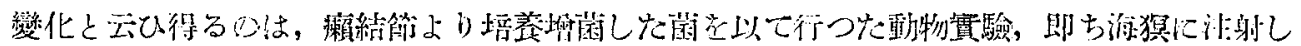

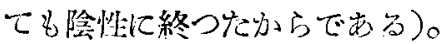

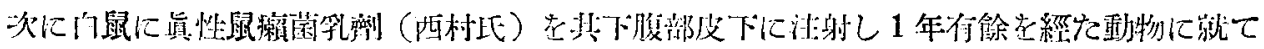

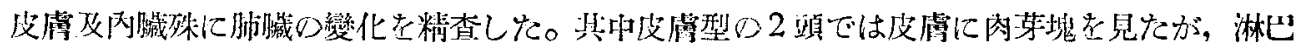

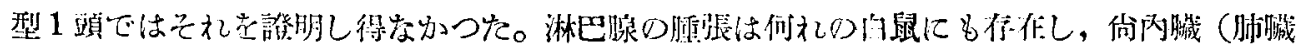

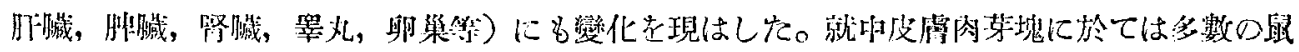

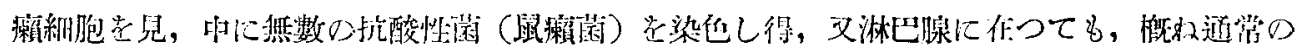

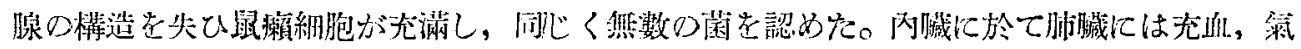

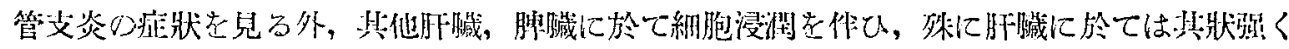

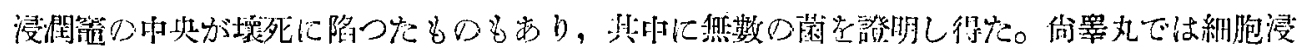

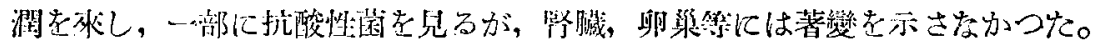

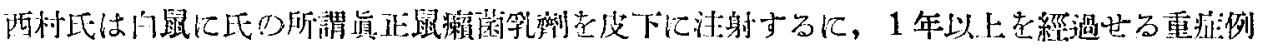

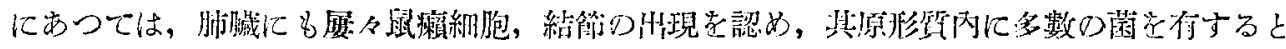

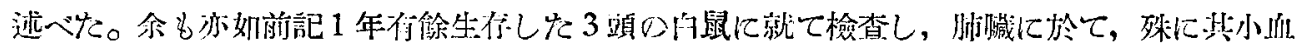

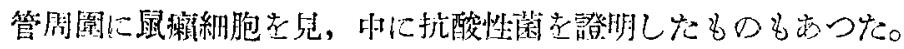

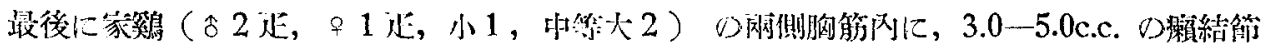

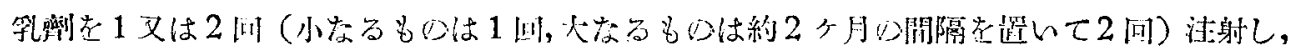

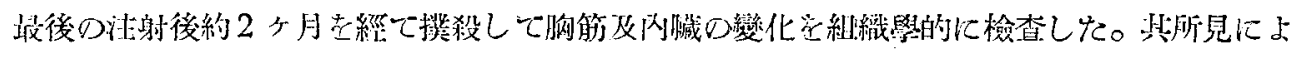

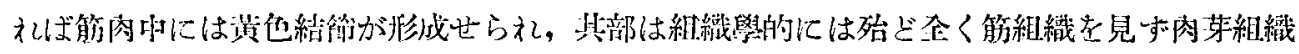

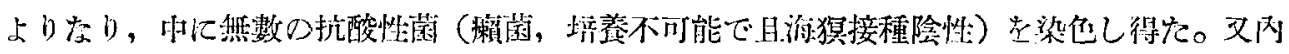




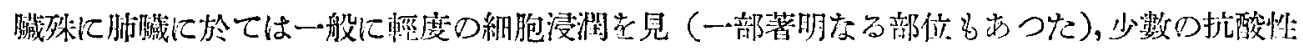

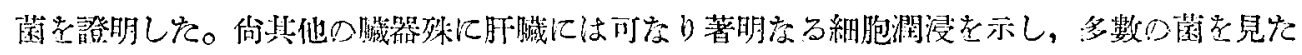

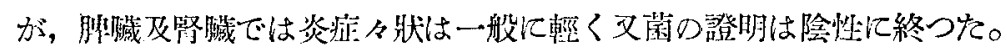

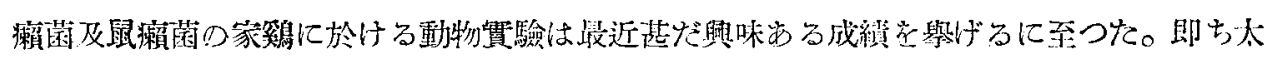

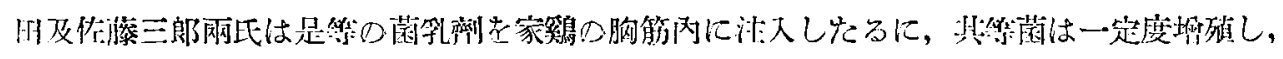

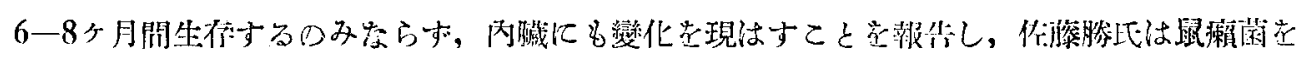

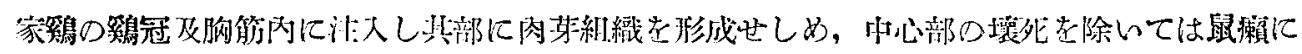

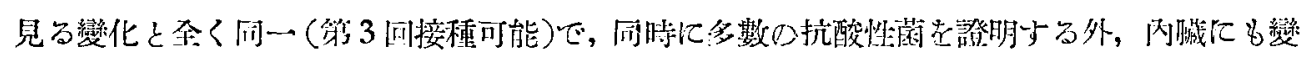

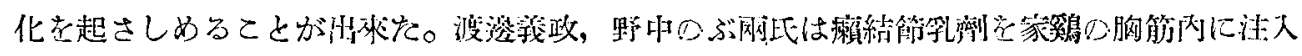

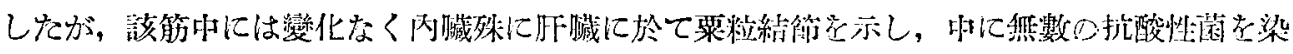

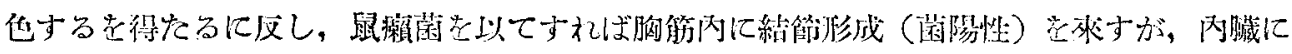

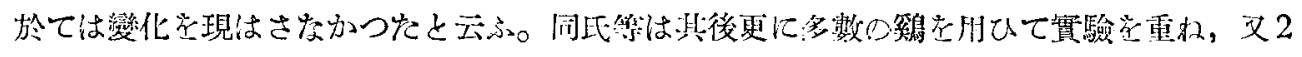

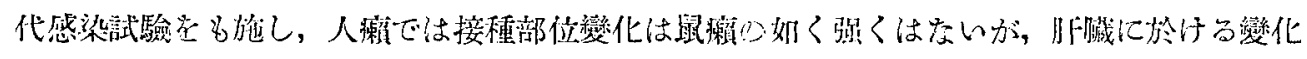

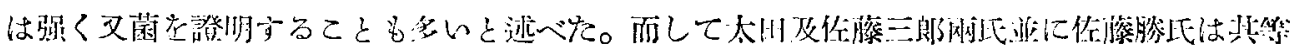

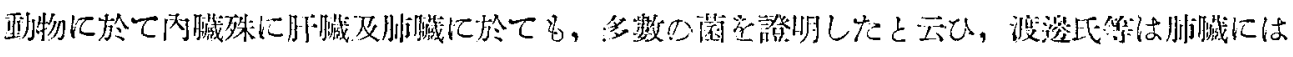

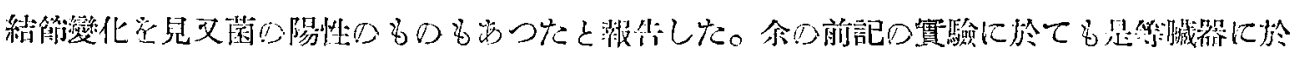

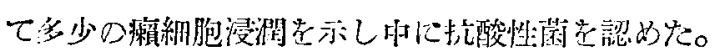

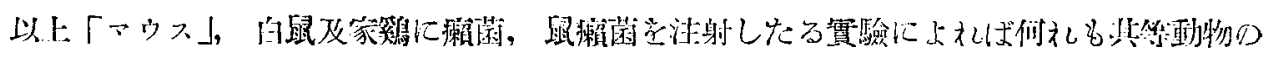

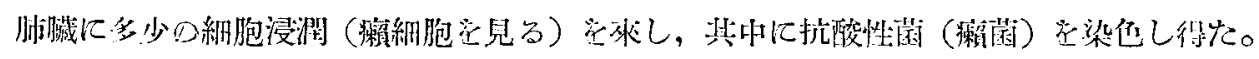

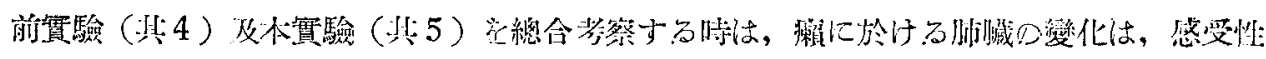

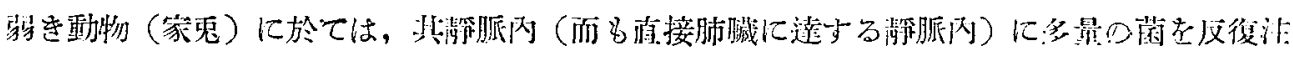

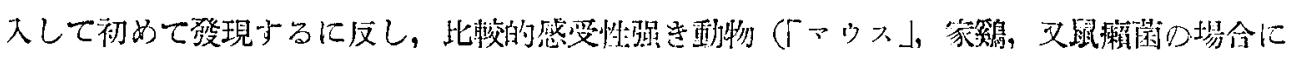

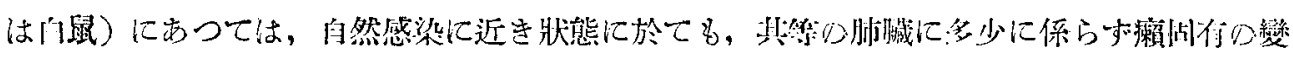

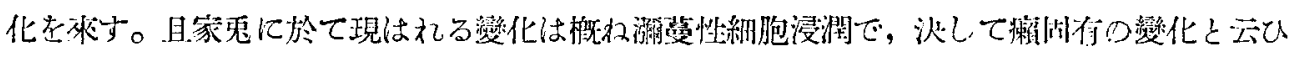

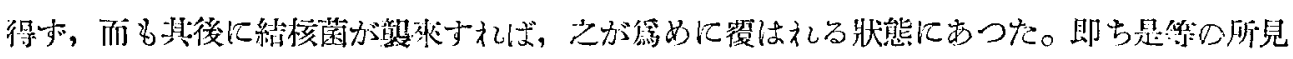

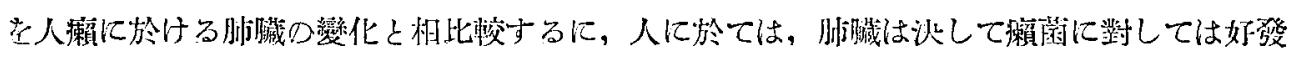

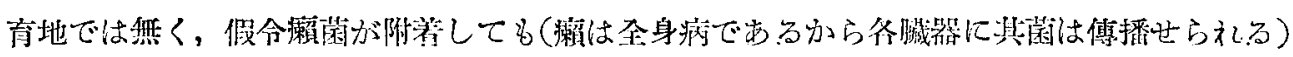

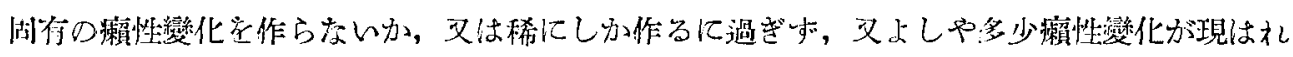

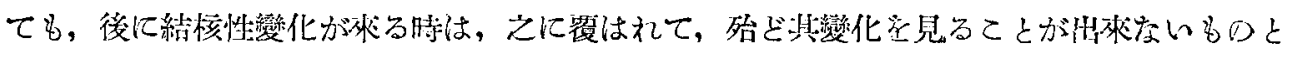

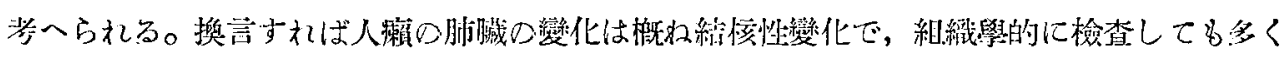

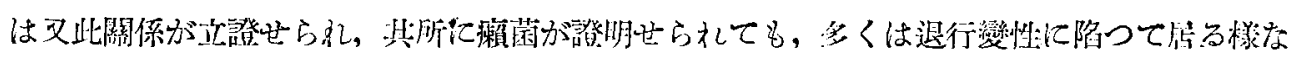

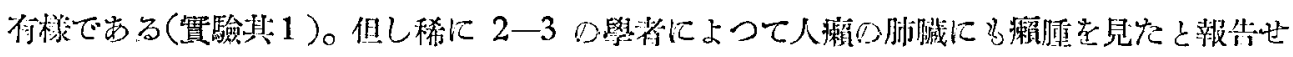


られて處るが，是は唯例外と見做すべきである。

\section{第4 章結諭}

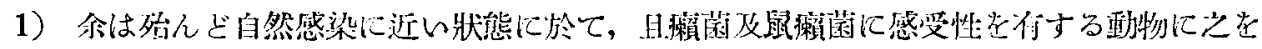

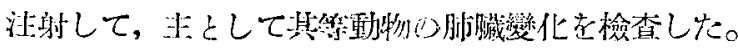

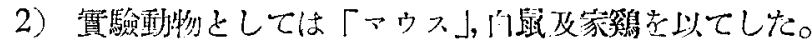

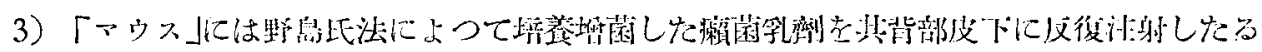

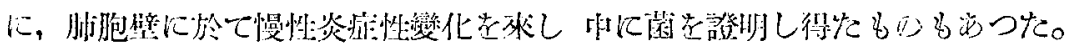

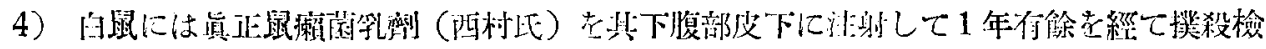

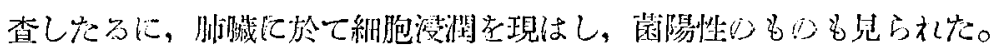

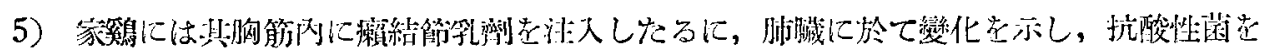
見计得行。

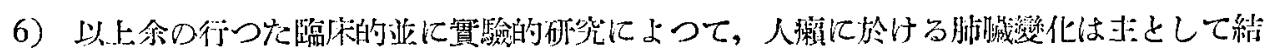

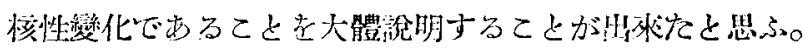

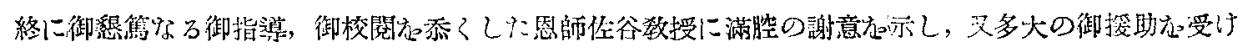

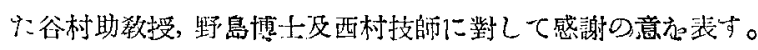

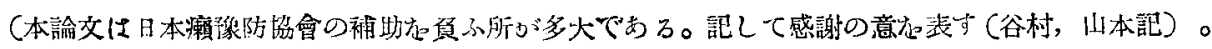

\section{主要 文 献}

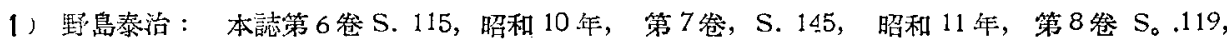

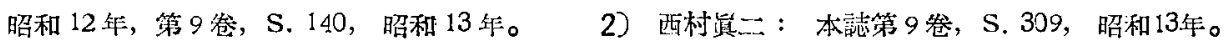

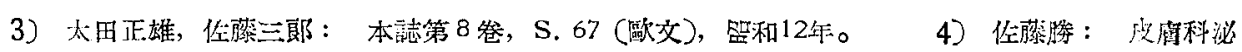

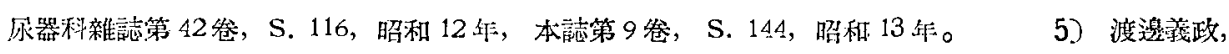

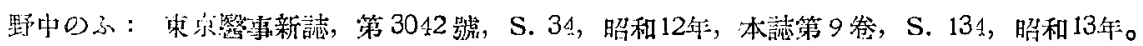

(特揭 昭和 13 年 11 月 21 日受稿)

\section{附 圖 說 明}

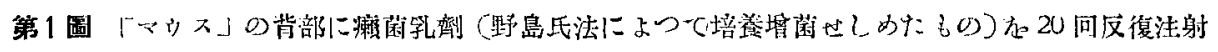

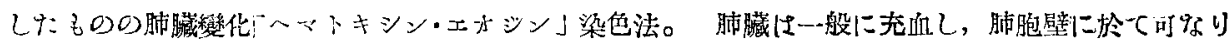
高庤察細胞浸潤光見る。

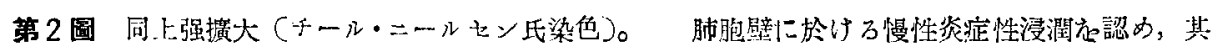

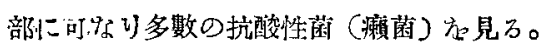

( 25 ) 
本

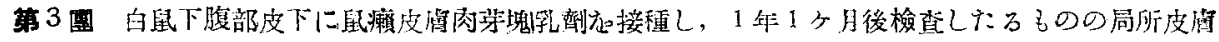

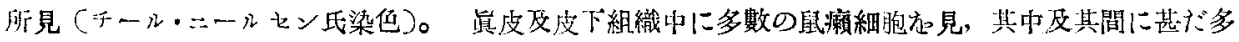

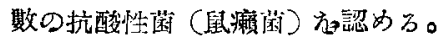

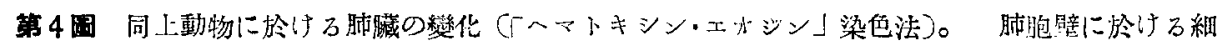

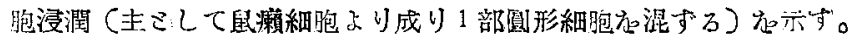

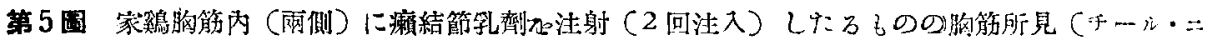

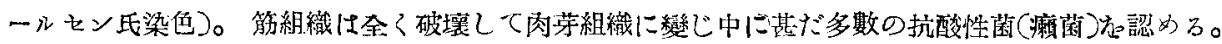

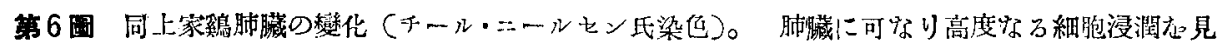
30 

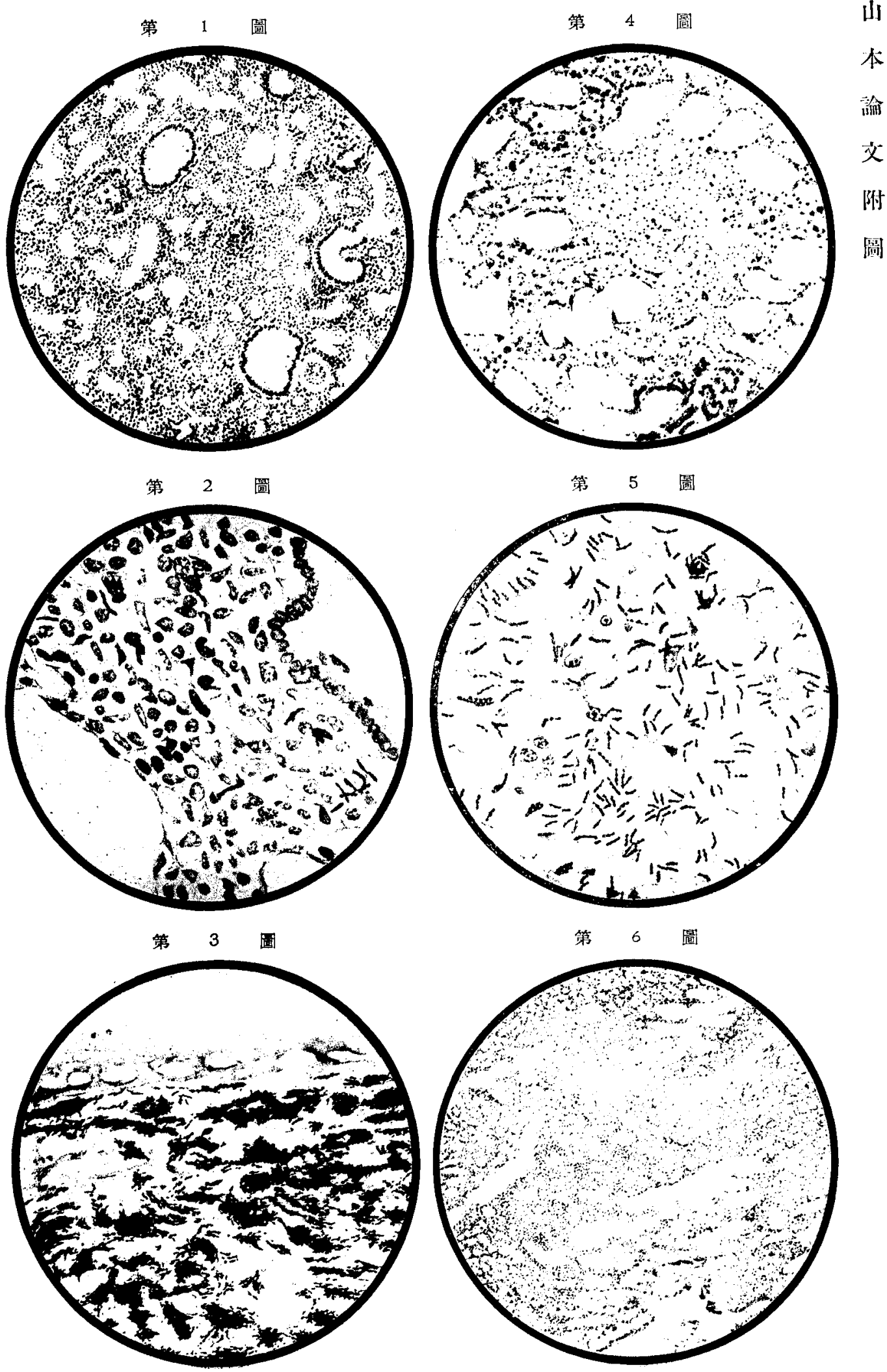


\title{
KLINISCHE UND EXPERIMENTELLE UNTERSUCHUNGEN ÜBER DIE VERÄNDERUNGEN DER LUNGEN BEI LEPRA.
}

\author{
V. ÜBER LUNGENVERÄNDERUNGEN BEI MÄUSEN, \\ WEISSEN RATTEN UND HÜHNERN.
}

\section{Von}

\section{Dr. Mitsutaro Yamamoto.}

[Aus der Dermato-Urologischen Klinik der kaiserlichen Universität zu Osaka (Vorstand: Prof. Dr. Y. Satani]

In diesen Versuchen wurden Mäusen, weißen Ratten und Hühnern Menschenlepra - und Rattenleprabazillen eingespritzt und verschiedene Organe, insbesondere die Lungen histologisch untersucht.

Bei den Mäusen konnte die Emulsion von Leprabazillen, welche nach der Nojima'schen Methode mehr oder weniger deutlich angereichert worden waren, in das subkutane Gewebe des Rückens wiederholt injiziert werden. In der Alveolarwand der Lungen zeigte sich eine chronische Entzündung, wobei z. T. hier und da Bazillen nachzuweisen waren.

Weiße Ratten, denen sog. echte Rattenleprabazillen nach Nishimura (s. Bd. IX. S. 309, 1938 dieser Zeitschrift) in die Bauchhaut injiziert worden waren, wurden nach über einem Jahr getötet und untersucht. Man konnte in den Lungen zellige Infiltration und hier und da vereinzelt Bazillen nachweisen.

Bei Hühnern wurden in die beiderseitigen Brustmuskel Leprabazillen (Emulsion der Knoten) 12 mal eingespritzt. In den betreffenden Muskeln waren die Bazillen mehr oder weniger deutlich vermehrt und in den Lungen war eine leichte, z. T. mäbige Zellinfiltration nachzuweisen; teilweise waren hier säurefeste Bazillen gefärbt.

\section{Erklärung der Abbildungen.}

Fig. 1. Tötung und histologische Untersuchung einer Maus, der 20 mal hintereinander Leprabazillen subkutan injiziert worden waren. Färbung mit Hämatoxylin-Eosin. Lungen allgemein hyperämisch, Alveolarwand mässig infiltriert.

Fig. 2. Starke Vergrösserung eines Präparats vom sleichen Tier. Färbung nach Ziehl. 
Neelsen. In der Alvsolarwand sieht man eine chronische Entzündung, und es lassen sich dabei ziemlich zahlreiche Leprabazillen nachweisen.

Fig. 3. Weisse Ratte, der Emulsion eines Hautgranuloms subkutan eingespritzt worden war; histologische Untersuchung 13 Monate später. Färbung nach Ziehl-Neelsen. Im Korium und subkutanen Gewebe waren zahlreiehe Rattenleprazellen zu sehen; in diesen und ihier Umgebung waren massenhaft Bazillen vorhanden.

Fig. 4. Histologisches Bild des gleichen Tiers mit Hämatoxylin-Eosin gefärbt. Zellinflitrate in den Alveolarwänden, die hauptsächlich aus Rattenleprazellen und einex kleinen Menge von Rundzellen bestanden.

Fig. 5. Muskelpräparat eines Hahns, in dessen Brustmuskel 2 mal Leprabazillen injiziert worden waren. Das Muskelgewebe ist gänzlich zerstört und in ein Granulom umgewandelt, in dem sehr viele Bazillen nachgewiesen werden konnten.

Fig. 6. Lungenpräparat vom gleichen Tier. In der Lunge ist eine ziemlich hochgradige Infiltration sichtbar. 